\title{
Biometrical genetic analysis of luteovirus transmission in the aphid Schizaphis graminum
}

\author{
ME Burrows ${ }^{1}$, MC Caillaud ${ }^{2}$, DM Smith ${ }^{1}$ and SM Gray ${ }^{1}$ \\ ${ }^{1}$ USDA-ARS Plant Protection Research Unit, Department of Plant Pathology, Cornell University, Ithaca, NY, USA and \\ ${ }^{2}$ Biology Department, Ithaca College, Ithaca, NY, USA
}

\begin{abstract}
The aphid Schizaphis graminum is an important vector of the viruses that cause barley yellow dwarf disease. We studied the genetic architecture of virus transmission by crossing a vector and a non-vector genotype of $S$. graminum. F1 and F2 hybrids were generated, and a modified line-cross biometrical analysis was performed on transmission phenotype of two of the viruses that cause barley yellow dwarf: Cereal yellow dwarf virus (CYDV)-RPV and Barley yellow dwarf virus (BYDV)-SGV. Our aims were to (1) determine to what extent differences in transmission ability between vectors and non-vectors is due to net additive or non-additive gene action, (2) estimate the number of loci that determine transmission ability and (3) examine the nature of genetic correlations between transmission of CYDV-RPV and BYDV-SGV. Only additive effects contributed significantly
\end{abstract}

to divergence in transmission of both CYDV-RPV and BYDVSGV. For each luteovirus, Castle-Wright's estimator for the number of effective factors segregating for transmission phenotype was less than one. Transmission of CYDV-RPV and BYDV-SGV was significantly correlated in the F2 generation, suggesting that there is a partial genetic overlap for transmission of these luteoviruses. Yet, $63 \%$ of the F2 genotypes transmitted CYDV-RPV and BYDV-SGV at significantly different rates. Our data suggest that in $S$. graminum, the transmission efficiency of both CYDV-RPV and BYDV-SGV is regulated by a major gene or set of tightly linked genes, and the transmission efficiency of each virus is influenced by a unique set of minor genes.

Heredity (2007) 98, 106-113. doi:10.1038/sj.hdy.6800909; published online 4 October 2006

Keywords: virus transmission; aphid genetics; greenbug; luteovirus; Barley yellow dwarf virus; Cereal yellow dwarf virus

\section{Introduction}

It is well known that insect populations vary in their ability to transmit viruses to plants and animals (Gubler and Rosen, 1976; Gooding, 1996; Bencharki et al., 2000; Gray et al., 2002; Lazzaro et al., 2004). However, very little is known about the genetic regulation of virus transmission. HH Storey (Storey, 1932) was the first to determine that transmission of Maize streak geminivirus to maize (Zea mays L.) by leafhoppers was under genetic control. He maintained 'active' and 'inactive' (vector and non-vector) genotypes of leafhoppers (Cicuadulina mbila Naude), and crossed these populations to determine that transmission was inherited via a sex-linked, dominant gene. The inheritance of virus vector competence in other leafhopper species has since been investigated. The transmission phenotype of Beet curly top hybrigeminivirus was found to be heritable in Eutettix tenellus (Baker) (Bennett and Wallace, 1938), and transmission of Potato yellow dwarf nucleorhabdovirus (PYDV) is sex linked or autosomal in Aceratagallia sanguinolenta (Prov.) (Black, 1943). Populations of Agallia constricta (van Duzee) were selectively bred for high and low transmission phenotype of two

Correspondence: Dr SM Gray, USDA-ARS Plant Protection Research Unit, Department of Plant Pathology, Cornell University, Tower Road, Ithaca, NY 14853, USA.

E-mail: smg3@cornell.edu

Received 16 May 2006; revised 24 July 2006; accepted 30 August 2006; published online 4 October 2006 different viruses, PYDV and wound-tumor virus (now Clover wound tumor phytoreovirus) (Nagaraj and Black, 1962). More recently, the role of genetics in the transmission of human diseases by mosquitoes has been intensively investigated. The susceptibility or refractiveness of mosquitoes (Aedes spp and Culicoides spp) to viral diseases has generally been found to involve one major gene (Gubler and Rosen, 1976; Hardy et al., 1978; Miller and Mitchell, 1991; Tabachnick, 1991). However, in other systems, vector competence is multigenic (Tardieux et al., 1991; Tabachnick, 1994). Several quantitative trait loci influencing transmission of Dengue-2 flavivirus (Bosio et al., 2000) and La Crosse bunyavirus (Anderson et al., 2005) in the mosquitoes Aedes aegypti and Ochlerotatus spp have been identified. However, specific genes controlling vector competence in insects have not been cloned. Knowledge of the genes and proteins involved in the transmission process would be useful for the development of novel disease control strategies that target insect-virus interactions.

Aphids are the most successful and numerous insect vectors of plant viruses. Considerable information is known about the biology of aphid-virus interactions and the viral determinants that regulate the specificity of transmission. However, the aphid factors regulating virus transmission are not well studied. Aphids are amenable to genetic investigation and the genetics of several ecologically important phenotypes have been dissected, including alate production (Weisser and Braendle, 2001; Caillaud et al., 2002; Braendle et al., 
2005a, b), insecticide resistance (Rider and Wilde, 1998; Rider et al., 1998), virulence on plants (Puterka and Peters, 1989, 1990), host preference (Via, 1991; Hawthorne and Via, 2001; Tosh et al., 2004), and lifecycle patterns (Zhang and Zhong, 1990; Dedryver et al., 1998). While the intraspecific variation of aphids to transmit a virus has long been known (Bjorling and Ossiannilsson, 1958; Price et al., 1971), the genetics of virus transmission is just beginning to be explored (Papura et al., 2002; Dedryver et al., 2005; Burrows et al., 2006). Studies to date have focused on the transmission of the viruses causing barley yellow dwarf disease in cereal crops and wild grass species.

The viruses that cause barley yellow dwarf are members of two genera in the viral family Luteoviridae, Polerovirus and Luteovirus (Miller and Rasochova, 1997). The icosahedral virions contain a positive sense, singlestranded RNA encapsidated by two proteins: a major $22 \mathrm{kDa}$ coat protein and a minor $72 \mathrm{kDa}$ read-through protein. Both proteins are involved in regulating virus transmission efficiency (Van den heuvel et al., 1993; Chay et al., 1996; Gildow, 1999; Brault et al., 2005). Luteoviruses are phloem limited and transmitted from plant to plant solely by aphids in a circulative, non-propagative manner (Gray and Gildow, 2003). Ingested virions are actively transported across gut epithelial cell cytoplasm in vesicles and released into the hemocoel. To be transmitted into a plant, the virions accumulate at the surface of the accessory salivary glands and are actively transported across the cells and deposited into the salivary duct. The virus does not replicate in any tissue of the aphid.

There is a great deal of specificity among the seven characterized species of virus causing barley yellow dwarf and five well-studied aphid vector species. Although all aphids can ingest any virus while feeding on the phloem of an infected plant, not all viruses are transmitted by all aphid genotypes. Failure to transmit a particular virus is regulated by an inability of the virus to be transported across the gut or salivary tissue. The ability to move through one tissue is independent of movement through the other tissues (Gray and Gildow, 2003). As mentioned, both viral proteins are involved in the transport process, but presumably they must interact with genetically regulated aphid components at each of the independent tissues.

Previous research on the inheritance of luteovirus transmission phenotype in aphids found Sitobion avenae transmission of Barley yellow dwarf virus (BYDV)-PAV to be a polygenic trait inherited in an additive manner (Papura et al., 2002; Dedryver et al., 2005). Burrows et al. (2006) examined F1 and F2 hybrids derived from two parental genotypes of Schizaphis graminum differing in their ability to transmit two viruses, Cereal yellow dwarf virus (CYDV)-RPV (Polerovirus) and BYDV-SGV (Luteovirus). Segregation of the transmission phenotype for both viruses was observed in the F1 and F2 populations, indicating that the transmission phenotype was under genetic control and the parents were heterozygous for genes involved in virus transmission. Additional studies determined that gut and salivary barriers were operating to prevent virus transmission in the non-vector genotypes, and that these barriers were segregating independent of one another (Burrows et al., 2006). In the present study, we expand on the work presented in Burrows et al.
(2006). Data from the same F1 generation and an expanded collection of F2 hybrids are used to perform a biometrical analysis of virus transmission. First, we use a modified version of line-cross analysis (Mather and Jinks, 1982; Kearsey and Pooni, 1996) to reveal the relative contributions of additive, dominance and epistatic effects to genetic differentiation between a vector and a non-vector parental line. We asked whether there is a net difference between the additive effects of the genes in the vector and non-vector parents, whether the genes in the vector parent tend, on average, to be dominant over those of the non-vector parent (and vice versa) and whether there are net epistatic interactions between the genes of the vector and non-vector parents. Secondly, we estimated the number of segregating factors responsible for behavioral differences between parental lines using the Castle-Wright estimate incorporating modifications suggested by Cockerham (1986) and Zeng (1992). Last, we examined the nature of the genetic correlation in transmission ability of two luteoviruses, BYDV-SGV and CYDV-RPV.

\section{Materials and methods}

\section{Generation of F1 and F2 crosses}

Virus-free genotypes of $S$. graminum were maintained parthenogenetically as described by Katsar and Gray (1999). The parental genotype F (Sg-F) (Porter et al., 1997) was a gift from John Burd (USDA, ARS, Stillwater, OK, USA) and is an efficient vector of CYDV-RPV and BYDVSGV (Gray et al., 1998). Parental genotype SC (Sg-SC) was collected in South Carolina, and is an inefficient vector (non-vector) of CYDV-RPV and BYDV-SGV (Gray et al., 1998)

To induce sexual forms for mating, aphids colonizing caged barley plants were transferred from growth chambers maintained at $20^{\circ} \mathrm{C}$ ( $18 \mathrm{~h}$ light) to chambers maintained at $15^{\circ} \mathrm{C}\left(12 \mathrm{~h}\right.$ light) or $13^{\circ} \mathrm{C}(11 \mathrm{~h}$ light $)$ and observed weekly for males and sexual females. To produce F1 hybrids, virgin female Sg-SC were placed in cages with male Sg-F. Sg-SC does not produce males, and thus a reciprocal cross was not possible. To generate the F2 cross, F1 genotypes were placed in the same environmental conditions as the parents to induce sexual aphids. Resulting virgin females and males were mated randomly. No matings of the same genotype were permitted. We chose this method because the parental genotypes used for our crosses are drawn from natural populations, and are thus likely to be heterozygous for most loci (Lynch and Walsh, 1998). Eggs from the parental and F1 crosses were collected as described by Via (1992) and stored for 3 months at $0-4{ }^{\circ} \mathrm{C}$. To induce hatching, eggs were placed in dishes containing moist filter paper and fresh barley tissue and incubated at $20^{\circ} \mathrm{C}$. First instar nymphs that hatched and survived were individually transferred to barley plants and allowed to develop parthenogenetically reproducing genotypes that were maintained as described previously (Katsar and Gray, 1999).

\section{Virus transmission}

Transmission assays were performed essentially as described by Gray et al. (2002). Briefly, aphids were placed on source material, which had been infected 
approximately 5 weeks previously. Aphids were allowed to feed for a $48 \mathrm{~h}$ acquisition access period and then transferred at a rate of five aphids per plant to 16 individual oat plants (Avena byzantina K. Koch cv. Coastblack). Four oat plants were inoculated with aphids, that had fed on healthy oat plants (five aphids per plant) as a negative control. Aphids were allowed to feed on oat plants for a 5-day inoculation access period before being fumigated. Symptoms were allowed to develop in the greenhouse for 3-5 weeks. Plants with weak symptoms were tested for the presence of virus using double antibody sandwich enzyme-linked immunosorbent assay (DAS-ELISA) as described previously (Gray et al., 1998). All tissue used as source material was tested using DAS-ELISA to confirm virus infection. Transmission tests for each F1 genotype were repeated 35 times over a 12-month period. Transmission tests for each F2 genotype were repeated 2-5 times from January to June 2004 and January to August 2005. Sg-F and Sg-SC were included in each experiment as positive and negative controls, respectively.

\section{Statistical analysis}

All data were analyzed using the Statistical Analysis System (SAS Institute Inc., Cary, NC, USA). Transmission phenotypes of the F2 generation were first subjected to an analysis of variance, for BYDV-SGV and CYDV-RPV separately, to determine which characters showed significant genetic variation (segregation) (PROC MIXED). 'F2 genotype' was considered as a random factor. For visualizing the data, means of each level of fixed effects (parents Sg-F and Sg-SC, F1 and F2 genotypes) were calculated in PROC MIXED as leastsquares means (LSMEANS statement).

We tested the generation means for goodness-of-fit to genetic models incorporating additive or dominant effects using the joint scaling test of Mather and Jinks (1982) as described by Kearsey and Pooni (1996). The joint scaling test has been shown to be applicable to nonhomozygous lines (as Sg-F and Sg-SC are) as long as mating between close relatives did not occur (Lynch and Walsh, 1998). Some generations (e.g. F2) have much larger variance among individuals than others due to genetic segregation, and there may be large differences in family sizes. This heterogeneity within the generation makes the accuracy of the means unequal. The joint scaling test adjusts for this by weighting the means differently in the regression analysis (Kearsey and Pooni, 1996). The weighted regression analysis and the $\chi^{2}$ test were implemented using PROC REG.

The minimum number of segregating factors involved in genetic divergence in virus transmission between $\mathrm{Sg}-\mathrm{F}$ and Sg-SC parents was estimated using the method first developed by Castle and Wright (Castle, 1921) and then modified by Lande (Lande, 1981) for use with nonhomozygous populations. We use here the method to estimate $n_{\mathrm{e}}$ suggested by Cockerham (1986) that corrects for sampling variances in the estimates of parental populations. As described in Lynch and Walsh (1998), after computing $n_{\mathrm{e}}$ using the Cockerham equation (Cockerham, 1986), we substituted this estimate in an expression suggested by Zeng (Zeng et al., 1990; Zeng, 1992) that takes into account possible linkage and inequality of allelic effects. In this estimate, the haploid number of chromosomes in S. graminum is $4(2 n=8)$ (Mandrioli et al., 1999).

Genetic correlations between transmission of BYDVSGV and CYDV-RPV were calculated in the F2 generation as Pearson's product-moment correlations of clone means (Via, 1991) using PROC CORR. If the same loci influence transmission of BYDV-SGV and CYDV-RPV, then cross-environment correlations in F2 are expected to be significantly different from zero and positive.

\section{Results}

\section{Development of F1 and F2 generations}

As reported previously (Burrows et al., 2006), a cross between a female inefficient vector genotype, Sg-SC, and a male vector genotype, Sg-F, produced 13 F1 hybrid genotypes. The $13 \mathrm{~F} 1$ genotypes were reared under the environmental conditions that induced sexual forms in the parents. Six of the F1 genotypes (F1-1, F1-4, F1-5, F1-9, F1-11 and F1-12) produced males, and 10 of the F1 genotypes (F1-1, F1-2, F1-3, F1-4, F1-5, F1-7, F1-9, F1-10, F1-11 and F1-12) produced females. Genotypes F1-6, F1-8 and F1-13 did not produce any males or females. Males and females were intermated to avoid inbreeding, producing an F2 generation. Multiple random crosses resulted in 1859 eggs. Three hundred and fifty-four of these eggs hatched, and 96 individual F2 fundatrices formed parthenogenetic colonies.

\section{Transmission phenotypes of the F2 hybrid generation}

In the F2 generation, transmission efficiency ranged from 0 to $100 \%$ for both CYDV-RPV and BYDV-SGV (Figure 1). Significant genetic variation for transmission phenotype was seen in the F2 generation for both CYDV-RPV and BYDV-SGV (CYDV-RPV: $F_{93,255}=6.0, P<0.001$; BYDVSGV: $\left.F_{93,254}=9.1, P<0.001\right)$. Transmission efficiency of the positive control, Sg-F, was stable throughout the experiment (CYDV-RPV: 76 $\pm 3 \%$; BYDV-SGV: $70 \pm 3 \%$ ). Transmission of either CYDV-RPV or BYDV-SGV by the negative control, Sg-SC, was rare ( $0 \pm 0 \%$ for both).

\section{Line-cross analysis}

The mean transmission efficiency of the F1 and F2 genotypes was intermediate between that of the parents (Table 1), indicating no directional dominance of either parent on transmission phenotype. If vector and nonvector aphids diverge primarily in genes with additive effects, then hybrid means for all generations should fall along the dotted lines joining the observed parental means in Figure 2. The extent to which the hybrid means are displaced from this line is proportional to the degree of dominance. In the presence of epistasis, the displacement for the F1 hybrids and the F2 hybrids is comparable (Lynch and Walsh, 1998). For both CYDV-RPV and BYDV-SGV transmission, hybrid means fall along the line (Figures 2a and b), suggesting that these characters are almost completely additive, and this was confirmed with the joint scaling test (Table 2).

We estimated the number of genes involved in the transmission phenotype for both CYDV-RPV and BYDVSGV. Biometrical estimates using the method suggested by Cockerham (1986) were low: $0.58 \pm 0.08$ for CYDVRPV and $0.60 \pm 0.11$ for BYDV-SGV. In S. graminum, using equation 9.27 of Lynch and Walsh (1998) with possible 


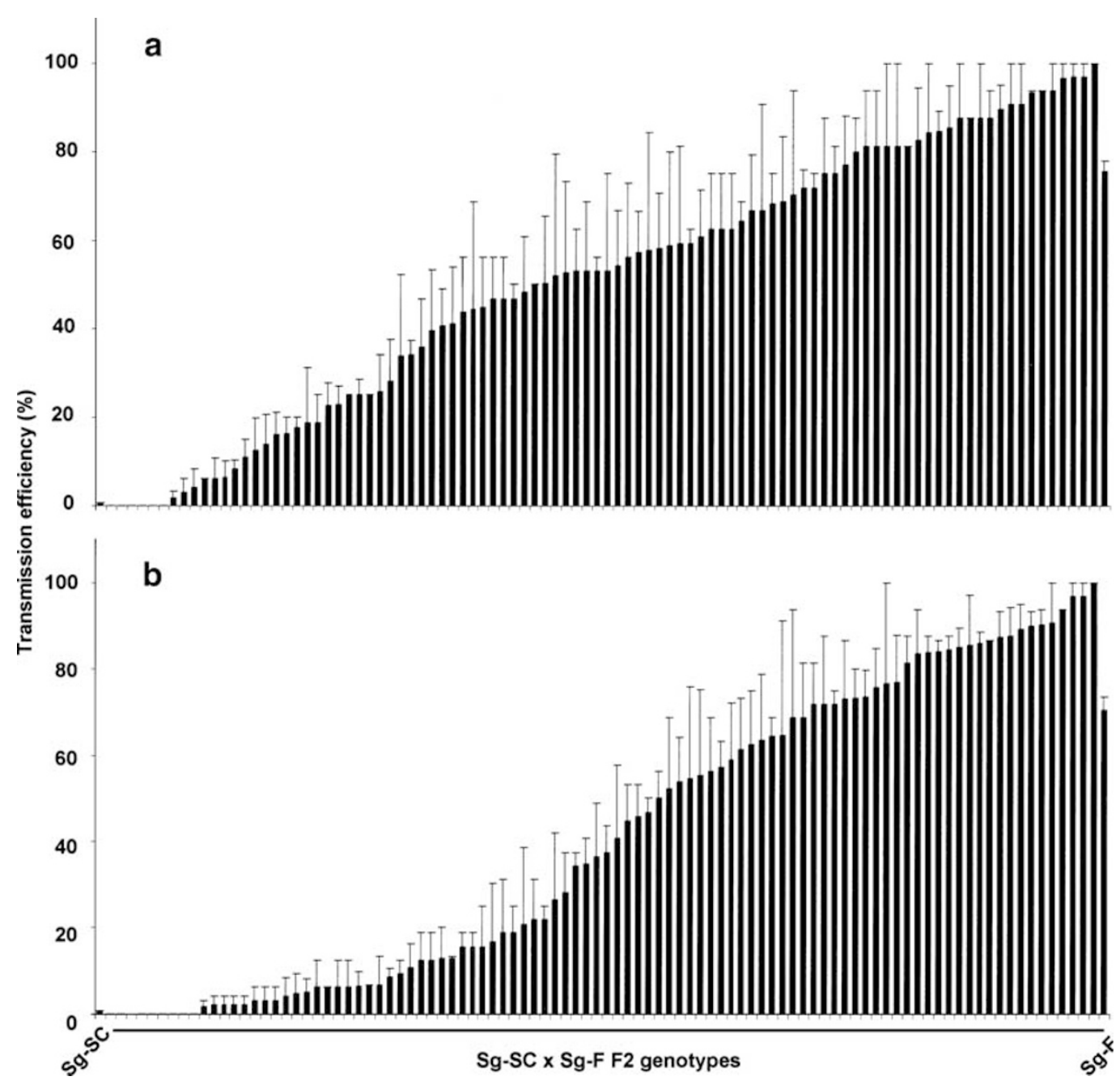

Figure 1 Transmission efficiency of CYDV-RPV (a) and BYDV-SGV (b) for 96 F2 hybrid clones of a cross between a non-vector (Sg-SC) and a vector (Sg-F) genotype of S. graminum. The mean transmission efficiency of Sg-SC and Sg-F are on the left and right-hand sides of the $x$ axis, respectively. F2 genotypes are arranged along the $x$ axis in order of increasing transmission efficiency. Each bar represents the mean of two to five experiments plus the standard error of the mean.

Table 1 Transmission efficiency of CYDV-RPV and BYDV-SGV for the parents, F1 and F2 hybrids

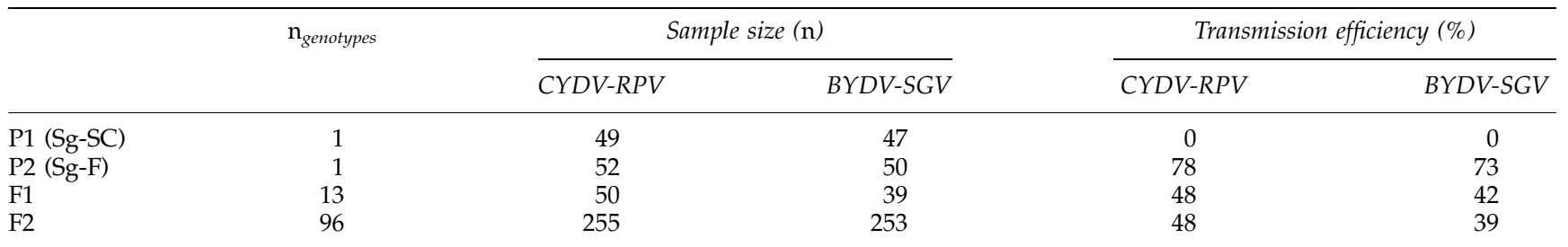

Abbreviations: BYDV = Barley yellow dwarf virus; CYDV = Cereal yellow dwarf virus.

Transmission efficiency was calculated as the number of plants that became infected out of the total number of plants inoculated with five viruliferous aphids per oat plant. Sixteen plants were included in each trial.

linkage (c) equal to $3 / 8$ and the inequality of allelic effects $\left(C_{\alpha}\right)$ equal to 1 , we find an $n_{\mathrm{e}}$ of 0.06 for BYDVSGV transmission and of 0.04 for CYDV-RPV transmission.

The relationship between CYDV-RPV and BYDV-SGV transmission was investigated by calculating the $r_{\mathrm{cm}}$ of Via (1991). The transmission of CYDV-RPV and BYDV-SGV were significantly correlated in both the F1 $\left(r_{\mathrm{cm}}=0.59, P<0.001\right.$; Burrows et al., 2006) and $\mathrm{F} 2$ $\left(r_{\mathrm{cm}}=0.40, P<0.001 ;\right.$ Figure 3$)$ generations, suggesting that there is a partial genetic overlap between transmission of CYDV-RPV and BYDV-SGV. The majority of F1 and F2 genotypes transmitted CYDV-RPV and BYDV-SGV at significantly different rates (F1, six of 13 genotypes; F2, 60 of 96 genotypes), showing that some genes uniquely influence transmission of either CYDVRPV or BYDV-SGV. Additionally, several F2 genotypes transmitted more efficiently than the vector parent 
110

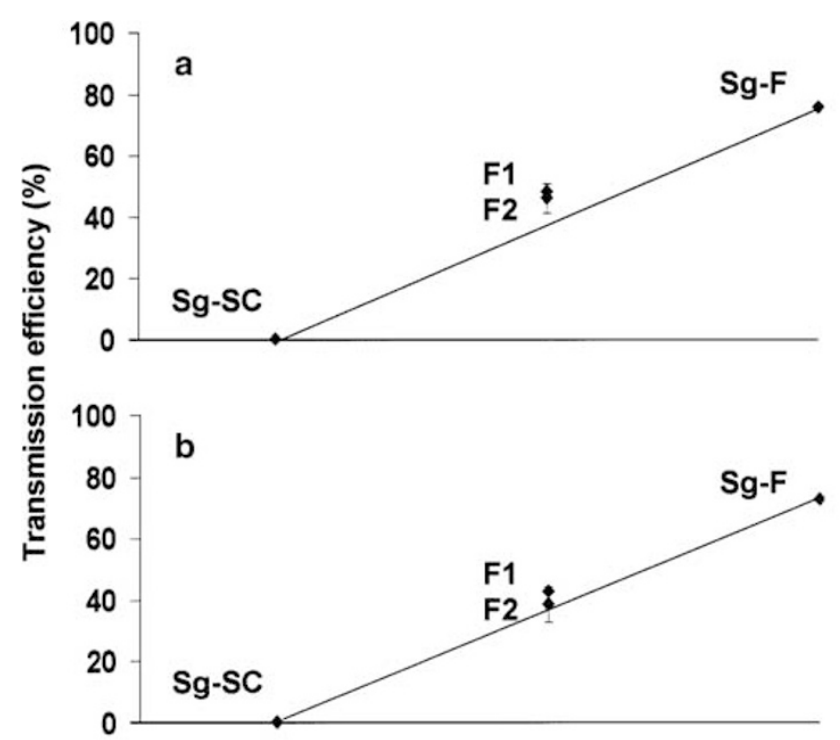

Figure 2 Mean transmission efficiency of CYDV-RPV (a) and BYDV-SGV (b) for the parents (Sg-SC and Sg-F), F1 and F2 hybrid genotypes. The solid line represents the weighted least-squares estimate of a simple additive model. Standard error bars are included for each mean.

Table 2 Parameter estimates for models incorporating additive and dominant effects

\begin{tabular}{|c|c|c|c|c|c|}
\hline & $\mathrm{m}$ & a & d & aa & $\chi^{2}$ \\
\hline \multicolumn{6}{|c|}{ Transmission of RPV } \\
\hline$y=m+x a$ & 0.540 & -0.530 & \multirow{3}{*}{0.007} & \multirow[b]{3}{*}{0.011} & $0.56^{\mathrm{NS}}$ \\
\hline$y=m+x a+x d$ & 0.541 & -0.530 & & & 0.52 \\
\hline$y=m+x a+x a a$ & 0.536 & -0.543 & & & 0.52 \\
\hline \multicolumn{6}{|c|}{ Transmission of SGV } \\
\hline$y=m+x a$ & 0.476 & -0.475 & \multirow{3}{*}{-0.017} & & $1.41^{\mathrm{NS}}$ \\
\hline$y=m+x a+x d$ & 0.474 & -0.491 & & & 1.28 \\
\hline$y=m+x a+x a a$ & 0.457 & -0.523 & & 0.066 & 0.55 \\
\hline
\end{tabular}

Abbreviations: $m$, mean (average phenotype of the two parents); $a$, additive genetic component of the expected mean; $d$, dominance genetic component of the expected mean; aa, additive by additive genetic component of the expected mean; $\mathrm{NS}=$ non-significant. See Kearsey and Pooni (1996, pp 19-33) for details.

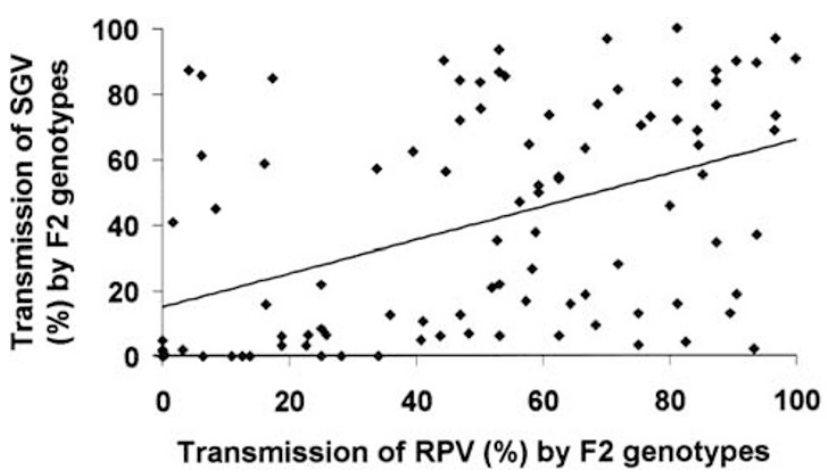

Figure 3 Genetic correlations between transmission efficiency of CYDV-RPV and BYDV-SGV for F2 hybrid genotypes of a cross between S. graminum genotypes Sg-SC and Sg-F. The line represents the Pearson's product-moment correlation of clone means (Via, 1991).
(Sg-F), indicating Sg-F was not homozygous for all genes facilitating transmission and there is transgressive segregation in the F2 genotypes (Figure 1).

\section{Discussion}

In this study, we examined the genetic basis of luteovirus transmission in S. graminum. Our main goal was to determine which of two alternative genetic models was more plausible: (a) a few major genes or (b) many genes, each with a small influence on the phenotype. If the difference in transmission ability between parents $\mathrm{Sg}-\mathrm{F}$ and Sg-SC is caused by a one to a few major segregating factors, then a search for molecular markers tightly linked to these loci is likely to be successful, and the eventual molecular characterization of these loci using a positional cloning approach is feasible.

The biometrical estimates we found are strikingly low (less than 1) and suggest that few loci explain differences in transmission ability between parents Sg-F and Sg-SC. It is tempting to speculate that a major gene influencing virus transmission segregates in our F2 generation. The biometrical estimation we used rests on several assumptions that, if not met, lead to an underestimation of the 'true' number of loci segregating in hybrid generations. It assumes unlinked loci, equality of allelic effects, additive gene action and that all the genes with a positive influence on the traits are sorted into one parental line and all those with negative influence into the other parental line (Lynch and Walsh, 1998). Although we were able to test for the adequacy of the additive gene action model, examining whether other assumptions of this method are met in our study is more difficult. Following the modification of the Castle-Wright method recommended by Lynch and Walsh (1998), most of the potential violations of these assumptions are taken into account in $c$ and $C_{\alpha}$. Yet, our estimates of the number of loci associated with transmission phenotype remain approximations. Our goal, however, was not to provide definite estimates of gene number for CYDV-RPV and BYDV-SGV transmission, but to place some bounds on the number of genes involved in transmission. From our results, it is clear that one major aphid gene (or a set of tightly linked genes) controls virus transmission. This is the one we detected with our estimate $n_{\mathrm{e}}$. This one major aphid gene (or a set of tightly linked genes) likely explains the significant positive genetic correlation observed between CYDV-RPV and BYDV-SGV transmission in both the F1 and F2 generation. Yet, other genes, contributing less to differences in transmission phenotype between $\mathrm{Sg}-\mathrm{F}$ and $\mathrm{Sg}-\mathrm{SC}$, and harder to detect with our biometrical estimates, also contribute to the variation in transmission phenotype. These loci will affect either CYDV-RPV or BYDV-SGV transmission and explain why many F2 genotypes can efficiently transmit one virus and poorly transmit the other virus. The availability of a finescale genetic map and the possibility of mapping BYDVSGV and CYDV-RPV transmission onto this linkage map would provide much better estimates of the gene number and their individual effects.

From this and previous studies (Papura et al., 2002; Dedryver et al., 2005), several trends have emerged. First, the transmission of luteoviruses is multigenic, and inheritance is generally additive in manner. Second, there is transgressive segregation of hybrid genotypes, 
that is, a number of F1 and F2 genotypes were found to transmit virus at a higher level of efficiency than that of the vector parent. Third, individual genotypes do not exhibit the same phenotype for transmission of all Luteoviridae. Taken together, we can conclude that transmission is a multigenic, non-dominant trait. There are few genes involved in transmission phenotype, some of which are shared and others which are isolate-specific. We can only speculate on the function of these genes at this time. One hypothesis is that the genes involved in transmission include receptors. A search for proteins that bind to virus using far-Western blots has been partly successful, and several proteins have been identified (Li et al., 2001; Seddas et al., 2004). However, the lack of genomic data for the aphid has limited the identification of many potentially influential proteins, and the lack of a reverse genetic system in the aphid has limited our investigations into their functionality. The adaptive immune system could also be involved in regulating virus transmission by recognition and response to nonself-particles. Little is known about immunity in aphids, and little is known about insect immune responses to viruses in general. Responses to bacterial, fungal and protozoal pathogens include melanization, phagocytosis and cellular encapsulation by hemocytes, as well as secretion of antimicrobial peptides (Leclerc and Reichhart, 2004; Levashina, 2004; Loker, 2004). However, the response to viral pathogens is considered to be distinct, as Drosophila genes involved in anti-bacterial and antifungal immunity are not induced by virus pathogens (Sabatier et al., 2003; Leclerc and Reichhart, 2004). An encapsulation immune response to a baculovirus was described in Helicoverpa zea (Trudeau et al., 2001). Other responses to viral pathogens could include apoptosis (Narayanan, 1998) or RNA interference (RNAi). RNAi is a sequence-specific targeting of pathogen RNA, which is initially induced by a double-stranded RNA, and has been found to be active against viruses in mosquitoes (Keene et al., 2004), Drosophila (Li et al., 2002) and shrimp (Robalino et al., 2004, 2005). An RNAi response to luteoviruses in aphids is considered unlikely since luteoviruses do not uncoat or replicate in the aphid host. In addition to immune responses, there could be conformational changes in the structural proteins of luteoviruses due to $\mathrm{pH}$ or other biochemical changes in the aphid. It could be postulated that any of these alterations to the virus could be isolate-specific, thus substantiating the results of our genetic analysis.

It has been postulated that symbionin, a protein produced in copious amounts in endosymbionts such as Buchnera in aphids (van den Heuvel et al., 1994) and Bemisia tabaci in whiteflies (Morin et al., 1999), is involved in stabilizing the virus in the aphid hemocoel and thus facilitating transmission (van den Heuvel et al., 1994). Symbionin is a homolog of the heat-shock protein GroEL of Escherichia coli, which is a member of the chaperonin 60 family of proteins (Morioka and Ishikawa, 1998). The N-terminal domain of PLRV binds symbionin from vector and non-vector aphids, as well as GroEL from E. coli (van den Heuvel et al., 1997). Aphids treated with antibiotics to eliminate endosymbionts are less efficient vectors of PLRV (van den Heuvel et al., 1994), which has led to the postulate that symbionin facilitates virion stability in the hemolymph and ultimate transmission by the aphid (van den Heuvel et al., 1994). Endosymbionts have been found to influence resistance to parasitic wasps (Oliver et al., 2005) and transovarial transmission of rice dwarf virus (Nasu, 1965). Buchnera is inherited through the maternal line. The facilitation of transmission by association with Buchnera is contradicted by the evidence in this study that CYDV-RPV transmission is facilitated by genes or factors inherited from the male (vector) parent. A reciprocal cross between a vector and a non-vector of PAV and RPV indicated some influence of maternal inheritance, but transmission phenotype could not be solely explained by this (Gray et al., 2006). In addition, we found that the hindgut and accessory salivary gland barriers to transmission were genetically controlled and separated in F2 hybrid genotypes, providing additional evidence for genetic control of luteovirus transmission in $S$. graminum, rather than endosymbiont influence. Although endosymbionts may play a role in stabilizing virus particles, we do not believe they determine vector competence in our system.

Our conclusions about the genetic architecture of virus transmission in S. graminum are based on a single cross. Our genetic analysis is therefore informative only about the alleles present in the two original parents, but it does not provide us with information about alleles present in the whole aphid population. More genes and more complex interactions among them may be detected as we add more parental genotypes to this study. Yet, our results provide an inroad to the molecular characterization of a gene having a major effect on transmission phenotypes in S. graminum. Although this may seem a monumental enterprise, ongoing improvements in genomic technologies are bringing the realization of this goal, in non-model organisms such as aphids, within reach.

\section{References}

Anderson JR, Schneider JR, Grimstad PR, Severson DW (2005). Quantitative genetics of vector competence for La Crosse virus and body size in Ochlerotatus hendersoni and Ochlerotatus triseriatus interspecific hybrids. Genetics 169: 1529-1539.

Bencharki B, Yamani ME, Zaoui D (2000). Assessment of transmission ability of Barley yellow dwarf virus-PAV isolates by different populations of Rhopalosiphum padi and Sitobion avenae. Eur I Plant Pathol 106: 455-464.

Bennett CW, Wallace HE (1938). Relation of the curly top virus to the vector, Eutettix tenellus. J Agric Res 56: 0031-0051.

Bjorling K, Ossiannilsson F (1958). Investigations on individual variation in the virus transmitting ability of different aphid species. Socker Handlingar 14: 1-13.

Black LM (1943). Genetic variation in the clover leafhopper's ability to transmit potato yellow-dwarf virus. Genetics 28: 200-209.

Bosio CF, Fulton RE, Salasek ML, Beaty BJ, Black WC (2000). Quantitative trait loci that control vector competence for dengue-2 virus in the mosquito Aedes aegypti. Genetics 156: 687-698.

Braendle C, Caillaud MC, Stern DL (2005a). Genetic mapping of aphicarus - a sex-linked locus controlling a wing polymorphism in the pea aphid (Acyrthosiphon pisum). Heredity 94: 435-442.

Braendle C, Friebe I, Caillaud MC, Stern DL (2005b). Genetic variation for an aphid wing polyphenism is genetically linked to a naturally occurring wing polymorphism. Proc $R$ Soc Lond Ser B 272: 657-664.

Brault W, Perigon S, Reinbold C, Erdinger M, Scheidecker D, Herrbach E et al. (2005). The polerovirus minor capsid 
protein determines vector specificity and intestinal tropism in the aphid. J Virol 79: 9685-9693.

Burrows ME, Caillaud MC, Smith DM, Benson EC, Gildow FE, Gray SM (2006). The genetic regulation of polerovirus and luteovirus transmission in the aphid Schizaphis graminum. Phytopathology 96: 828-837.

Caillaud MC, Boutin M, Braendle C, Simon JC (2002). A sexlinked locus controls wing polymorphism in males of the pea aphid, Acyrthosiphon pisum (Harris). Heredity 89: 346-352.

Castle WE (1921). An improved method of estimating the number of genetic factors concerned in cases of blending inheritance. Proc Natl Acad Sci USA 81: 6904-6907.

Chay CA, Gunasinge UB, Dinesh-Kumar SP, Miller WA, Gray SM (1996). Aphid transmission and systemic plant infection determinants of barley yellow dwarf luteovirus-PAV are contained in the coat protein readthrough domain and $17 \mathrm{kDa}$ protein, respectively. Virology 219: 57-65.

Cockerham CC (1986). Modifications in estimating the number of genes for a quantitative character. Genetics 137: 191-199.

Dedryver CA, Le Gallic JF, Gauthier JP, Simon JC (1998). Life cycle of the cereal aphid Sitobion avenae F.: polymorphism and comparison of life history traits associated with sexuality. Ecol Entomol 23: 123-132.

Dedryver CA, Riault G, Tanguy S, Le Gallic JF, Trottet M, Jacquot E (2005). Intra-specific variation and inheritance of BYDV-PAV transmission in the aphid Sitobion avenae. Eur J Plant Pathol 111: 341-354.

Gildow FE (1999). Luteovirus transmission mechanisms regulating vector specificity. In: Smith HG, Barker $\mathrm{H}$ (eds). The Luteoviridae. CABI: Wallingford, pp 88-111.

Gooding RH (1996). Genetic variation in arthropod vectors of disease-causing organisms: obstacles and opportunities. Clin Microbiol Rev 9: 301-320.

Gray SM, Caillaud MC, Burrows ME, Smith DM (2006). Transmission of viruses that cause barley yellow dwarf is controlled by different loci in the aphid, Schizaphis graminum. $J$ Insect Sci 6 (in press).

Gray SM, Chapin JW, Smith DM, Banerjee N, Thomas JS (1998). Barley yellow dwarf luteoviruses and their predominant aphid vectors in winter wheat grown in South Carolina. Plant Dis 82: 1328-1333.

Gray SM, Gildow FE (2003). Luteovirus-aphid interactions. Annu Rev Phytopathol 41: 539-566.

Gubler DJ, Rosen L (1976). Variation among geographic strains of Aedes albopictus in susceptibility to infection with dengue viruses. Am J Trop Med Hyg 25: 318-325.

Gray SM, Smith DM, Barbierri L, Burd J (2002). Virus transmission phenotype is correlated with host adaptation among genetically diverse populations of the aphid Schizaphis graminum. Phytopathology 92: 970-975.

Hardy JL, Apperson G, Asman SM, Reevers WC (1978). Selection of a strain of Culex tarsalis highly resistant to infection following ingestion of Western equine encephalomyelitis virus. Am J Trop Med Hyg 27: 313-321.

Hawthorne D, Via S (2001). Genetic linkage of ecological specialization and reproductive isolation in pea aphids. Nature 412: 904-907.

Katsar C, Gray S (1999). Rearing aphids to use in virus-vector studies. In: Maramorosch K, Mahmood F (eds). Maintenance of Animal/Human and Plant Pathogen Vectors. Science Publishers: Enfield, NH, pp 183-195.

Kearsey MJ, Pooni HS (1996). The Genetic Analysis of Quantitative Traits. Chapman \& Hall: London, UK.

Keene KM, Foy BD, Sanchez-Vargas I, Beaty BJ, Blair CD, Olson KE (2004). RNA interference acts as a natural antiviral response to $O^{\prime} n y o n g-n y o n g$ virus (Alphavirus; Togaviridae) infection of Anopheles gambiae. Proc Natl Acad Sci USA 101: 17240-17245.

Lande $R$ (1981). The minimum number of genes contributing to quantitative genetic variation between and within populations. Genetics 99: 541-553.
Lazzaro BP, Sceurman BK, Clark AG (2004). Genetic basis of natural variation in $D$. melanogaster antibacterial immunity. Science 303: 1873-1876.

Leclerc V, Reichhart JM (2004). The immune response of Drosophila melanogaster. Immunol Rev 198: 59-71.

Levashina EA (2004). Immune responses in Anopheles gambiae. Insect Biochem Mol Biol 34: 673-678.

Li C, Cox-Foster D, Gray SM, Gildow F (2001). Vector specificity of Barley yellow dwarf virus (BYDV) transmission: identification of potential cellular receptors binding BYDV-MAV in the aphid, Sitobion avenae. Virology 286: 125-133.

Li HW, Li WX, Ding SW (2002). Induction and suppression of RNA silencing by an animal virus. Science 296: 1319-1321.

Loker ES (2004). Invertebrate immune systems - not homogeneous, not simple, not well understood. Immunol Rev 198: 10-24.

Lynch M, Walsh B (1998). Genetics and Analysis of Quantitative Traits. Sinauer Associates: Sunderland, MA.

Mandrioli M, Ganassi S, Bizzaro D, Manicardi GC (1999). Cytogenetic analysis of the holocentric chromosomes of the aphid Schizaphis graminum. Hereditas 131: 185-190.

Mather K, Jinks JL (1982). Biometrical Genetics, 3rd edn. Chapman \& Hall: London, UK.

Miller BR, Mitchell CJ (1991). Genetic selection of a flavivirusrefractory strain of the yellow fever mosquito Aedes aegypti. Am J Trop Med Hyg 45: 399-407.

Miller WA, Rasochova L (1997). Barley yellow dwarf viruses. Annu Rev Phytopathol 35: 167-190.

Morin S, Ghanim M, Zeidan M, Czosnek H, Verbeek M, Heuvel JFJ et al. (1999). A GroEL homologue from endosymbiotic bacteria of the whitefly Bemisia tabaci is implicated in the circulative transmission of Tomato yellow leaf curl virus. Virology 256: 75-84.

Morioka M, Ishikawa H (1998). Insect chaperonin 60: symbionin. Method Enzymol 290: 181-193.

Nagaraj AN, Black LM (1962). Hereditary variation in the ability of a leafhopper to transmit two unrelated plant viruses. Virology 16: 152-162.

Narayanan K (1998). Apoptosis: its role in microbial control of insect pests. Curr Sci 75: 114-122.

Nasu S (1965). Electron microscopic studies on transovarial passage of rice dwarf virus. Japan J Appl Entomol Zool 9: 225-237.

Oliver KM, Moran NA, Hunter MS (2005). Variation in resistance to parasitism in aphids is due to symbionts not host genotype. Proc Natl Acad Sci USA 102: 12795-12800.

Papura D, Jacquot E, Dedryver CA, Luche S, Riault G, Bossis M et al. (2002). Two-dimensional electrophoresis of proteins discriminate's aphid clones of Sitobion avenae differing in BYDV-PAV transmission. Arch Virol 147: 1881-1898.

Porter DR, Burd JD, Shufran KA, Webster JA, Teetes G (1997). Greenbug (Homoptera: Aphididae) biotypes: selected by resistant cultivars or preadapted opportunists? J Econ Entomol 90: 1055-1065.

Price RD, Muller I, Rochow WF (1971). Variation in transmission of an isolate of barley yellow dwarf virus by Rhopalosiphum padi. Phytopathology 61: 753-754.

Puterka GJ, Peters DC (1989). Inheritance of greenbug, Schizaphis graminum (Rondani) virulence to GB2 and GB3 resistance genes in wheat. Genome 32: 109-114.

Puterka GJ, Peters DC (1990). Sexual reproduction and inheritance of virulence in the greenbug, Schizaphis graminum (Rodani). In: Campbell RK, Eikenbary RD (eds). Aphid-Plant Genotype Interactions. Elsevier: Amsterdam, pp 289-318.

Rider SD, Wilde GE (1998). Variation in fecundity and sexual morph production among insecticide-resistant clones of the aphid Schizaphis graminum (Homoptera: Aphididae). J Econ Entomol 91: 388-391.

Rider SD, Wilde GE, Kambhampati S (1998). Genetics of esterase-mediated insecticide resistance in the aphid Schizaphis graminum. Heredity 81: 14-19. 
Robalino J, Bartlett T, Shepard E, Prior S, Jaramillo G, Scura E et al. (2005). Double-stranded RNA induces sequence-specific antiviral silencing in addition to nonspecific immunity in a marine shrimp: convergence of RNA interference and innate immunity in the invertebrate antiviral response? J Virol 79: 13561-13571.

Robalino J, Browdy CL, Prior S, Metz A, Parnell P, Gross P et al. (2004). Induction of antiviral immunity by double-stranded RNA in a marine invertebrate. J Virol 78: 10442-10448.

Sabatier L, Jouanguy E, Dostert C, Zachary D, Dimarcq J-L, Bulet $\mathrm{P}$ et al. (2003). Pherokine-2 and -3: two Drosophila molecules related to pheromone/odor-binding proteins induced by viral and bacterial infections. Eur J Biochem 270: 3398-3407.

Seddas P, Biossinot S, Strub J-M, Dorsselaer AV, Regenmortel MHVV, Pattus F (2004). Rack-1, GAPDH3, and actin: proteins of Myzus persicae potentially involved in the transcytosis of Beet Western yellows virus particles in the aphid. Virology 325: 399-412.

Storey HH (1932). The inheritance by an insect vector of the ability to transmit a plant virus. Proc $R$ Soc Lond Ser $B$ 112: $46-60$.

Tabachnick WJ (1991). Genetic control of oral susceptibility to infection of Culicoides variipennis with bluetongue virus. Am J Trop Med Hyg 45: 666-671.

Tabachnick WJ (1994). Genetics of insect vector competence for arboviruses. Adv Dis Vector Res 10: 93-108.

Tardieux I, Poupel O, Lapchin L, Rodhain F (1991). Analysis of inheritance of oral susceptibility of Aedes aegypti to dengue-2 virus using isofemale lines. J Med Entomol 28: 518-521.

Tosh C, Vamvatsikos P, Hardie J (2004). A highly viable cross between Aphis fabae (Homoptera: Aphididae) clones with different plant preference. Environ Entomol 33: 1081-1087.

Trudeau D, Washburn JO, Volkman LE (2001). Central role of hemocytes in Autographa californica M. nucleopolyhedrovirus pathogenesis in Heliothis virescens and Helicoverpa zea. J Virol 75: 996-1003.

van den Heuvel JFJM, Verbeek M, Wilk FVD (1994). Endosymbiotic bacteria associated with circulative transmission of potato leaf roll virus by Myzus persicae. J Gen Virol 75: 2559-2565.

van den Heuvel JFJM, Bruyere A, Hogenhout SA, Ziegler-Graff V, Brault V, Verbeek M et al. (1997). The N-terminal region of the luteovirus readthrough domain determines virus binding to Buchnera GroEL and is essential for virus persistence in the aphid. J Virol 71: 7258-7265.

Van den heuvel J, Verbeek M, Peters D (1993). The relationship between aphid-transmissibility of Potato leafroll virus and surface epitopes of the viral capsid. Phytopathology 83: 1125-1129.

Via S (1991). The genetic structure of host plant adaptation in a spatial patchwork: demographic variability among reciprocally transplanted pea aphid clones. Evolution 45: 827-852.

Via S (1992). Inducing the sexual forms and hatching the eggs of pea aphids. Entomol Exp Appl 65: 119-127.

Weisser WW, Braendle C (2001). Body colour and genetic variation in winged morph production in the pea aphid. Entomol Exp Appl 99: 217-223.

Zeng Z-B (1992). Correcting the bias of Wright's estimates of the number of genes affecting a quantitative character: a further improved method. Genetics 131: 987-1001.

Zeng Z-B, Houle D, Cockerham CC (1990). How informative is Wright's estimator of the number of genes affecting a quantitative character? Genetics 126: 235-247.

Zhang GX, Zhong TS (1990). Experimental studies on some aphid life-cycle patterns and the hybridization of two sibling species. In: Campbell RK, Eikenbary RD (eds). Aphid-Plant Genotype Interactions. Elsevier: Amsterdam, pp 37-42. 